\title{
Sistemas de comunicación por imagines para niños autistas en el comienzo de la trayectoria: análisis y re-diseño de un sistema
}

Aida Almeida aidalmeida87@gmail.com

Paula Tavares ptavares@ipca.pt

Jorge Marques jorgetmarques@gmail.com

IPCA - Instituto Politécnico do Cávado e do Ave, Portugal

\section{Reference}

Resumen

Palabras clave

Abstract

Keywords
Almeida, Ainda; Tavares, Paula; Marques, Jorge; (2012) "Sistemas de comunicación por imagines para niños autistas em el comienzo de la trayectoria: análisis y re-diseño de un sistema", p. 198-201. In: Barbosa, Helena; Quental, Joana [Eds] Proceedings of the 2nd International Conference of Art, Illustration and Visual Culture in Infant and Primary Education. São Paulo: Blucher, 2015. ISSN 2318-695X, ISBN: 978-989-98185-0-7 DOI 10.5151/edupro-aivcipe-38

En la educación especial para autistas el método principal de la comunicación se hace con imágenes que hacen posible la comunicación entre profesores y alumnos. El gran problema de un niño autista es la enfermedad que afecta la comunicación del niño. A partir del analisis del sistema de comunicación vigente - Las cifras del Sistema de Comunicación (PEC) - se detectaron algunas inconsistencias en los símbolos utilizados, como son la falta de informidad y usabilidad visual. Así, este trabajo parte de la propuesta de cambiar, renovando el sistema. Nos proponemos a la creación de un conjunto de símbolos uniforme, coherente y convincente. Una vez que, desde el punto de vista del diseño y la ilustración, consideramos como esencial para la enseñanza del autista un establecimiento de determinada calidad en las imágenes e ilustraciones utilizadas en este universo. La investigación se centrará en el campo de la ilustración y el producto se sentará en el intento de reformular el sistema de comunicaciones implementada hoy en día, con el objetivo principal de hacer la comunicación fácil e inmediata entre los niños autistas, los profesores, padres y amigos. Es decir, buscamos la eficacia de comunicación entre el autista y los que los rodean.

Autismo, comunicación por imágenes, tarjetas ilustradas

In the special education for autism the mains method of communication is done with images, to make possible the communication between teachers and students, since one of the mains symptoms of this disease are its severe communication problems that presents. After the knowledge of the communication systems - Picture Exchange Comunication System (PECS) - it was noted that there are inconsistency in the symbols used, they don't have neither uniformity nor are visually pleasing. In an attempt to change this, it is proposed a renewal of this system, creating uniform, consistent and appealing symbols. It s essential to the establishment of quality in the illustrated images in autism education. The research will focus on the field of illustration and new illustrations will be created in an attempt to recreate the comunication system implemented nowadays, with the principal aim to making easier and more direct the comunication between autistic children and teachers/ parents/friends. This research seeks a more effective visual communication between autistic children and those around them. It is based on the PECS system in order to standardize the language making the communication more efficient and enjoyable. The illustrations will play an informative role, associated with the PECS system's own lexicon.

Autism, communication by images, illustrated cards 
and International Conference Art, Illustration and Visual Culture in Infant and Primary Education $2^{\circ}$ Congreso Internacional

Arte, llustración y Cultura Visual en Educación Infantil y Primaria
Congresso Internaciona

de Arte, Ilustração e Cultura Visual

na Educação Infantil e Primária

\section{Introducción}

\section{Desarrollo}

Figura 1. Tetzchner, v. S., Martinsen Harald. Introdução à Comunicação Aumentativa e Alternativa. Porto, 2000. sistema de signos logograficos BLISS

Figura 2.Tetzchner, v. S., Martinsen Harald. Introdução à Comunicação Aumentativa e Alternativa. Porto, 2000. Sistema PIC
El sistema de comunicación de imágenes es la forma más rápida y más eficaz para la comunicación entre los niños autistas y personas que los rodean. Fue creado en el año 80 de Roxanna Mayer Johnson, este sistema se compone de 8.000 símbolos que representan una amplia variedad de imágenes.

Los niños que tienen autismo son incapaces de comunicarse debido a una discapacidad neurológica y por lo tanto no hablan. Por eso es necesario crear alternativas para esta comunicación sea posible. Es a través de la imagen, sea ella fotográfica, ilustraciones o pictogramas que la comunicación se lleva a cabo.

Después de conocer el sistema se ha detectado, que hay una inconsistencia en los símbolos utilizados, no hay uniformidad ni son agradables visualmente, es decir, son de frágil usabilidad. Nos proponemos a la reformación, a la constitución de un sistema, partiendo de la consideración de que deberá ser uniforme, coherente y atractivo. En efecto, es nuestro objetivo el establecimiento de un determinado nivel de calidad en las imágenes ilustradas en la educación, especialmente a de los niños autistas.

Nos centramos en el aprendizaje de los niños y en la educación especial para el autismo que vamos trabajar e estudiar. Para entenderlo lo que es el autismo nos hemos basado en las teorías de Tetzcher Mzrtinsen. Para el autor, el autismo es un problema neurológico, donde hay dificultades en el lenguaje y en las comunicaciones y por eso las relaciones con la gente son una dificultad. Reaccionan mal cuando las rutinas fijas se cambian o hay cambios ambientales. Esto se demuestra a través de la ira y la ansiedad. (2002, p.83). Para evitar este problema en la comunicación es importante crear un sistema auxiliar para que los autistas puedan comunicar y desarrollar sus actividades Harmoniosamente.

Este es el sistema que tiene como base este estudio y es parte de la vida del autista en la escuela.

Existen varios sistemas de comunicación que ayudan a la comunicación del autismo, tales como signos logográficos Bliss, pictogramas PIC, SPC, REBUS y lexigramas. Siendo los sistemas más utilizados los pictogramas SPC O PIC tanbien Ilamado como PECS.

El sistema Bliss (Figura 1). Son señales logográfico / ideográfico. Fue creada originalmente "para formar un lenguaje internacional, usando el chines como un modelo y con el objetivo de contribuir para la paz" (Tetzchner, vol. S. et al 2000). Fue utilizado para los niños con discapacidades físicas y sin poder hablar. Dispone de 100 signos.
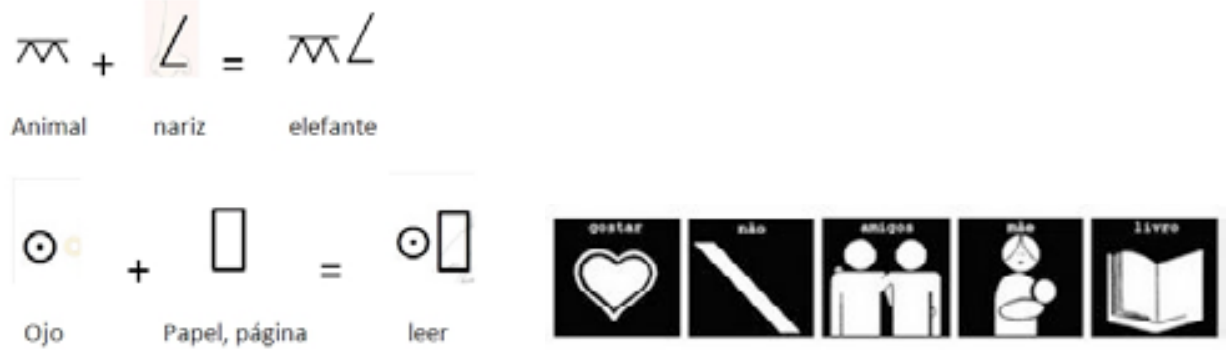

El sistema de comunicación designado como pictogramas PIC (Pictogram Ideogram Communication), en la Figura 2, existe un sistema muy complicado tal como el sistema BLISS. Contiene 1.300 signos.

La figura 3 es el sistema SPC (símbolos pictóricos para la comunicación). Tiene cerca de 3000 signos, es muy popular debido a la gran cantidad de símbolos. El sistema de REBUS (Figura 4), un sistema diferente, tiene cerca de 2000 signos y segundo Tetzchner "En la actualidad, el uso del sistema Rebús es muy raro". 
2nd International Conference Art, Illustration and Visual Culture in Infant and Primary Education de Arte, llustração e Cultura Visual

na Educação Infantil e Primária
Figura 3. El sistema SPC (Símbolos Pictóricos para la Comunicación), imagen retirada da la internet, MayerJohnson.

Figura 4. Tetzchner, v. S., Martinsen Harald. Introdução à Comunicação Aumentativa e Alternativa. Porto, 2000. Sistema de signos REBUS
Figura 5. Tetzchner, v. S., Martinsen Harald. Introdução à Comunicação Aumentativa e Alternativa. Porto, 2000 Lexigrama.

Figura 6. Prototipo del proyecto ilustrativo

\section{Conclusión}

\section{Referencias}

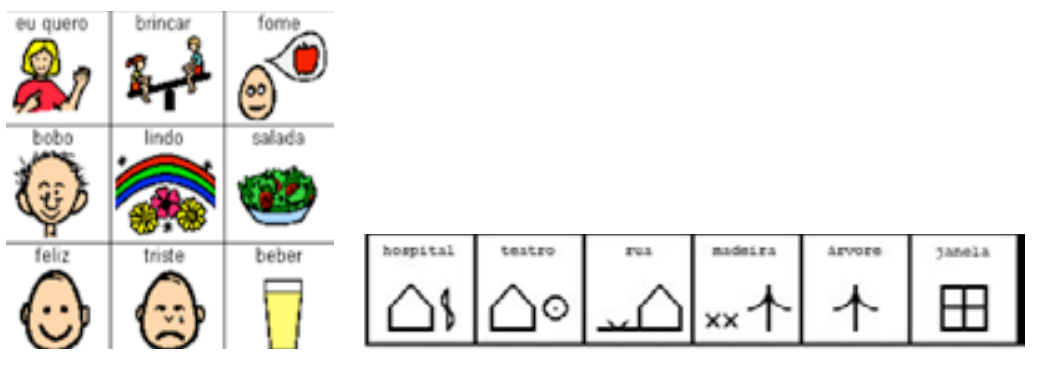

El Lexigrama (Figura 5), es también un sistema de signos que, aunque no se ha completado todavía puede ser considerado una alternativa. Un conjunto de 9 elementos pueden combinarse para formar un significado. Aunque esté en estudio. Un sistema con elementos muy simples, como un cuadrado o un círculo. Por otra parte, y por último, el sistema de comunicación alternativa también se considera imágenes (dibujos o fotografías reales) una forma de comunicación alternativa.

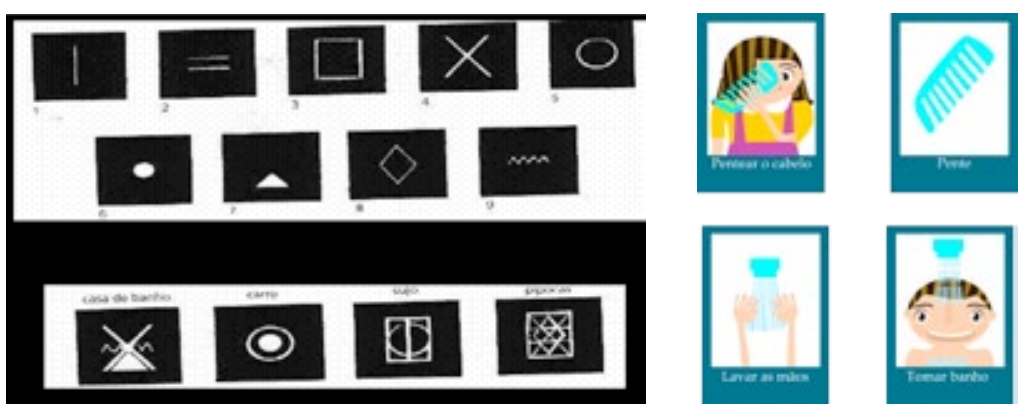

Es a partir del sistema comunicación PECS que se producirá el prototipo de la propuesta que estamos trabajando. Este proyecto consiste en la creación de ilustraciones consistentes entre ellas, es objectivo la unidad y calidad, es decir proponemos "mejorar" las ilustraciones del cotidiano de comunicación para niños autistas.

Este proyecto se está desarrollando en el "Mestrado de llustração e Animação" en el Instituto Politécnico do Cávado e do Avé. Como el sistema tiene sobre miles de imágenes, para este trabajo se pretende hacer sólo algunas categorías que pueden ser posteriormente aumentadas el número de ilustraciones. Hasta el momento hemos desarrollado un conjunto de diez ilustraciones para cada categoría elegida. Las categorías son elegidas con base a la importancia personal, es decir lo que se considera como fundamental para la vida de un niño. Elegimos las categorías de espacio la escuela, la higiene personal, y el espacio familiar. Como son ejemplo las figuras aquí presentadas (figura 6), las imágenes representan acciones de higiene personal. Véase 'cómo lavarse las manos'. Fue nuestra intención que las imágenes contengan elementos simples. En este caso que ilustren la representación de las manos y la representación del agua. Pretendemos una ilustración directa y sintética através de formas básicas y colores planos.

El momento actual de la investigación y proyecto nos hace intuir que lo vamos a concluir en tiempo útil de hacer la propuesta a las instituciones que trabajan todos los días con niños autistas. Presentarlo en esta conferência es la oportunidad de exponer el proyecto, recoger ideas e aportes para mejorarlo aún más.

Costa, J. , Moles A. Enciclopedia del Diseño, Imagen Didáctica. Ediciones Ceac Barcelona, 1991.

Tetzchner, v. S., Martinsen Harald. Introdução à Comunicação Aumentativa e Alternativa. Porto Editora, Porto, 2000

Tomkiewicz, S. O Autismo. Margem, 1987. p. 52-53-54, 13-14. 
$2^{\text {nd }}$ International Conference

Art, Illustration and Visual Culture in Infant and Primary Education
- Congreso Internaciona

y Cultura Visual en Educación Infantil y Primaria de Arte, llustração e Cultura Visual na Educação Infantil e Primária 